\title{
FORMAÇÃO E INTERVENÇÃO PROFISSIONAL EM SAÚDE PÚBLICA: PERCEPÇÕES DE PROFISSIONAIS DE EDUCAÇÃO FÍSICA
}

\author{
PROFESSIONAL TRAINING AND INTERVENTION IN PUBLIC HEALTH: \\ PERCEPTIONS BY PHYSICAL EDUCATION PROFESSIONALS
}

\author{
FORMACIÓN E INTERVENCIÓN EN SALUD PÚBLICA: PERCEPCIÓN DE \\ PROFESIONALES DE LA EDUCACIÓN FÍSICA
}

Ricardo Lira de Rezende Neves*, Luis Otávio Teles Assumpção**

\begin{abstract}
Palavras chave: Educação Física. Formação profissional. Intervenção. Sistema Único de Saúde.

Resumo: Neste artigo buscamos analisar as percepções de profissionais de Educação Física sobre os processos de formação e seus reflexos na atuação em serviços da Saúde Pública em Goiânia/GO. Realizamos entrevistas com nove trabalhadores de quatro instituições da Secretaria Municipal de Saúde desta cidade. O material coletado foi analisado a partir da técnica de Análise de Conteúdo, com apoio do software Webqda. O rigor empregado na sistematização dos dados se deu pelo uso da técnica de saturação teórica e empírica. Os resultados apontaram que os profissionais veem a formação inicial: tradicional e tecnicista; mais centrada no campo da iniciação esportiva, atividade física, exercícios físicos, escola/ didática e da academia de ginástica; e pouco focada nas necessidades dos serviços públicos de saúde, gerando fragilidade nesta dimensão da intervenção profissional.
\end{abstract}

Keywords: Physical Education. Professional Qualification Intervention. Unified Health System.

Palabras clave: Educación Física. Formación Profesional. Intervención Sistema Único de Salud.

Abstract: This article analyzes Physical Education professionals' perceptions about their training processes and the effects on their performance on public health work in Goiânia, Brazil. We conducted interviews with nine workers from four institutions of the Municipal Health Department. The material collected was examined under content analysis with support from Webqda software. Rigorous data systematization was conducted under the theoretical and empirical saturation technique. Results showed that professionals see their initial training as traditional and technical, more focused on the field of sports initiation, physical activity, exercise, school/didactics and fitness centers rather than on the needs of public health services, thus creating weakness in that dimension of professional intervention.

Resumen: En este artículo se analizan las percepciones de los profesionales de Educación Física acerca del proceso de formación y sus reflejos en el rendimiento de los servicios de salud pública en Goiânia, Estado de Goiás. Hemos realizado entrevistas con nueve trabajadores de cuatro instituciones de la Secretaría Municipal de Salud de esa ciudad. El material recopilado se analizo con la técnica de Análisis de Contenido, con el apoyo del software de Webqda. El rigor empleado en la sistematización de los datos se dio por el uso de la técnica de saturación teórica y empírica. Los resultados mostraron que los profesionales entienden la formación inicial como: tradicional y tecnicista, más centrada en el campo de la iniciación deportiva, actividad física, ejercicios físicos, escuela/didáctica y del gimnasio, y poco centrada en las necesidades de los servicios públicos de salud, lo que genera fragilidad en esta dimensión de la intervención profesional.
*Universidade Federal de Goiás. Goiânia, GO, Brasil.

E-mail: rrneves@gmail.com

${ }^{* *}$ Universidade Católica de Brasília. Taguatinga, DF, Brasil. E-mail: luiso@pos.ucb.br

Recebido em: 06-10-2016 Aprovado em: 11-06-2016

(c) (1) (8) Licence 


\section{INTRODUÇÃO E OBJETIVO}

Este artigo apresenta como temática central os desajustes entre a formação dos Profissionais de Educação Física (PEF) e as intervenções profissionais na Saúde Pública (SP), especialmente em serviços de saúde de uma região de Goiânia.

Atualmente, percebemos a inserção de PEF em diversas unidades de saúde do país, contudo, sempre em menor quantidade comparada às outras profissões de saúde. Esta situação pode ser explicada por diversos aspectos e condicionantes históricos do campo da Educação Física (EF). Um deles seria a desresponsabilização da EF quanto à formação e estruturação de fazeres e saberes voltados às necessidades do trabalho no Sistema Único de Saúde (SUS). Mesmo diante deste descompromisso histórico, Freitas, Carvalho e Mendes (2013) destacam que foi possível perceber a institucionalização dos conteúdos e das ações da EF na SP, o que provocou mudanças nos "modos de fazer o trabalho em saúde", principalmente a partir da criação da Política Nacional de Promoção de Saúde no ano de 2006.

Na busca pelo preenchimento desta lacuna, a Secretaria Municipal de Saúde de Goiânia (SMS) incluiu PEF em seu quadro profissional, de forma mais incisiva, através de concurso público, no ano de 2002. Atualmente, constam entre seus profissionais $31 \mathrm{PEF}$, lotados da seguinte forma: 20 nos Centros de Atenção Psicossocial (CAPS); quatro nas subsedes da SMS, chamados de Distritos Sanitários (DS); dois em Centros de Atenção Integral à Saúde (CAIS); dois em Centros de Referência de Atenção à Saúde de Idosos (CRASPI); um em Centro de Convivência de Saúde Mental; um em Hospital Psiquiátrico; um na Divisão de saúde mental da SMS (nível central) (GOIÂNIA, SMS - DGETS, 2013).

O desenvolvimento de ações destes profissionais, além de incluir fazeres e saberes próprios do campo da EF nestas unidades de saúde, possibilitou também a realização de pesquisas. Na primeira, Cirqueira (2009) refletiu acerca da cultura corporal no espaço de Atenção à Saúde Mental e concluiu que as atividades recreativas são muito positivas no processo de sociabilização dos usuários dos serviços dos CAPS. Defendeu que as ações devem ser sistematizadas numa "intencionalidade pedagógica" e centradas nos conteúdos da cultura corporal de movimento, assim seriam importantes porque contribuiriam com a legitimação da presença do professor de EF na Saúde Mental.

Martinez (2014), em sua tese de doutoramento, problematizou a organização do trabalho nos Núcleo de Apoio à Saúde da Família (NASF) e as contribuições da EF. Demonstrou os avanços e dificuldades apresentados pelos profissionais e gestores das equipes multiprofissionais desta unidade de saúde.

Por outro ângulo, Furtado et al. (2015) buscaram compreender as características e rotinas da realidade das intervenções do trabalho de professores de EF nos CAPS de Goiânia. Concluíram que o trabalho dos PEF aproxima-se dos princípios do CAPS, contudo, apesar de avanços relevantes, os profissionais ainda estão aprendendo a lidar com os novos desafios colocados pelo campo da SP e da Saúde Mental.

Estas produções demonstram um momento importante das investigações quanto à temática deste ensaio. Reforçam, deste modo, que a Educação Física precisa ampliar as pesquisas empíricas considerando como objeto de análises as bases de atuação deste profissional, de maneira especial quanto às competências, habilidades e parâmetros para avaliação da aproximação ou não do trabalho com os princípios do SUS (COUTINHO, 2011). 
Pretendemos contribuir com o avanço destas investigações ao analisar a percepção dos PEF sobre seus processos de formação inicial e suas relações com as intervenções profissionais em unidades de saúde em Goiânia.

Nas análises das percepções destes profissionais, quanto aos elementos constituintes da formação e do trabalho especializado, como os conteúdos e saberes utilizados em suas ações, nos apoiamos nos conceitos de campo, capitais e habitus, relacionados à teoria da prática (BOURDIEU, 1983, 1989). Relacionados à sociologia das profissões nos baseamos nos conceitos de expertise, autonomia, credencialismo e status (FREIDSON, 1998, 2001).

Para Freidson (1998), as profissões que gozam de prestígio e status a partir dos constructos expertise, credencialismo e autonomia sinalizam que suas atividades, saberes, competências e habilidades são diferenciadas. Estes assegurariam o monopólio da intervenção e legitimidade profissional. Para o autor, isso exigiria da profissão responsabilidades, dedicação à carreira e compromisso. Estes aspectos definiriam o grau de liberdade, status, autonomia $e$ independência nas tomadas de decisão, no caso desta investigação centrada no trabalho em serviços da Saúde Pública.

Já para Bourdieu (1989), os profissionais, ao acumularem em suas estruturas diferentes tipos de percepção, ação, classificação e distinção, formam seu habitus e como desdobramento estruturam diferentes gostos e práticas cotidianas assumidas individualmente e coletivamente. Habitus seriam estruturas estruturantes, ou seja, apresentariam propriedades típicas da posição social de quem a produz (apreciação, preferências, gostos, aspirações estão estruturadas em relação ao momento da ação) (BOURDIEU, 1983). O habitus do indivíduo e/ou do grupo depende do espaço social que envolve os sujeitos, variando conforme a experiência da cultura historicamente vivida, na educação, no lazer, no trabalho. É percebido, classificado e incorporado pelo sujeito e pelas instituições nas quais se estabelecem interações.

Em particular, para Bourdieu (1989), o habitus estrutura o capital cultural dos agentes no campo. Este tipo de capital estaria mais ligado aos processos de formação e educação realizados nos cursos das universidades, na escola e no próprio campo de atuação profissional. Por este motivo, estes dois conceitos são explorados para explicar as percepções dos PEF, trazendo à tona o uso de saberes e fazeres próprios do capital cultural, acadêmico e institucional.

A partir destes conceitos, discutimos como a formação inicial reverbera, desdobra-se e repercute nas propostas de trabalho dos PEF nas unidades pesquisadas, explicitando seus elementos de avanço e limites diante da realidade.

\section{METODOLOGIA}

A pesquisa de campo foi realizada na zona urbana da cidade de Goiânia, capital do estado de Goiás, especificamente na Secretaria Municipal de Saúde (SMS), através de um estudo exploratório (TEIXEIRA, 2001).

Optamos por realizar a pesquisa em uma região com 177.661 habitantes, caracterizando-se como um distrito misto em termos de organização dos serviços de saúde. Também por ser o único dos sete distritos que apresentava concomitantemente PEF em diferentes tipos de serviço, possibilitando demonstrar a diversidade e a especificidades da formação e do trabalho da EF nestes diferentes tipos de unidades, com suas características específicas na organização do trabalho. 
Para tanto, fizemos a opção pela abordagem qualitativa (CHIZZOTTI, 1995) por entender que, para conhecer a realidade e as contradições do contexto de trabalho das diferentes unidades de saúde, esta decisão metodológica seria a mais adequada.

A pesquisa foi desenvolvida com seis PEF trabalhadores das unidades atualmente e mais três PEF que, de alguma forma, desenvolveram trabalhos em anos anteriores ou esporadicamente nas unidades. Assim, nove PEF participaram voluntariamente da pesquisa. Foi usado como critério de inclusão dos sujeitos para o estudo: ser PEF efetivo, com diferentes idades e tempos de formação e intervenção profissional. A coleta de dados se deu por meio do contato com os locais de trabalho dos pesquisados. Iniciamos a pesquisa de campo em 02/10/2013 e a finalizamos em 13/05/2014.

$\mathrm{Na}$ coleta de dados fizemos entrevistas semiestruturadas abordando o contexto do trabalho e a formação dos PEF. A entrevista semiestruturada (TRIVIÑOS, 1987) contou com questionamentos básicos, apoiados nas teorias que delineamos para a operacionalização do material a ser analisado. As entrevistas duraram em média uma hora e dez minutos e foram realizadas individualmente em ambientes restritos dentro das quatro unidades de saúde. Os sujeitos assinaram o Termo de Consentimento Livre e Esclarecido e o projeto foi aprovado pela Escola de Saúde Pública da SMS e pelo Comitê de Ética em pesquisa da Universidade Federal de Goiás com o protocolo 414/11.

Fizemos a transcrição das entrevistas, o tratamento dos resultados, as inferências e a interpretação do material a partir da técnica de análise de conteúdo estabelecendo categorias temáticas conforme indica Bardin (1977). O material foi cadastrado em um software de apoio à análise qualitativa - WEBQDA. Buscamos também, nesta fase, realizar a análise de saturação empírica dos conteúdos das respostas dos entrevistados. Esta fase consistiu em determinar quais índices (temas) encontrados nas entrevistas se relacionavam com conceitos das teorias estruturantes do roteiro de entrevistas e das análises. Recorremos à técnica de saturação empírica dos dados como condição de evidenciar o rigor empregado na investigação e sistematização dos dados. Para Fontanella et al. (2011), esta técnica permite ir além de "fechar" a amostragem e decidir que "conjunto de dados" coletados e analisados fará parte do processo de organização, sistematização e exposição das temáticas/categorias elencadas pelo pesquisador (FONTANELLA et al., 2011, p. 389).

A partir dos delineamentos metodológicos apresentados, passamos agora a apresentar os resultados eas análises a partir do material coletado nas entrevistas. A título de esclarecimento, nesta exposição, utilizamos a sigla PEF seguida de um numeral para representar os sujeitos.

\section{A PERCEPÇÃO DOS PROFISSIONAIS DE EDUCAÇÃO FÍSICA SOBRE A FORMAÇÃO E A ATUAÇÃO NA SAÚDE PÚBLICA}

A formação de qualquer profissional atuante no campo da SP é fundamental e não seria diferente para a área da EF. As diferentes percepções dos PEF demonstram haver importantes elementos da formação que interferem na inserção, aceitação, intervenção e, consequentemente, na legitimação da EF e de seus profissionais nas unidades de saúde do contexto investigado.

Com maior destaque, os conteúdos das entrevistas voltaram-se para três categorias temáticas, quais sejam: as fragilidades da formação para a SP; a tradição dos currículos 
tecnicistas na área e suas influências na atuação em SP; e o confronto entre formação específica e/ ou ampliada. Todas essas temáticas apresentaram desdobramentos no processo de intervenção profissional nos diferentes serviços de saúde das unidades investigadas.

Nos discursos dos PEF evidenciou-se, com muita clareza, haver uma relativa lacuna e fragilidade da formação dos PEF em relação às questões, temas e assuntos referentes ao campo da SP.

Com efeito, constatamos nos discursos inapropriação e, por vezes, até mesmo ausência de conteúdos, disciplinas específicas desse universo da SP. Chamou-nos a atenção a relativa fraqueza da formação inicial, pouco específica e pouco direcionada para a atuação no campo da SP. As falas dos PEF 1 e 2 evidenciam esta questão.

[...] Específico da EF para a SP não tive nada, nem uma disciplina está dentro da nossa formação, na minha grade [currículo de formação] não tive nada de Saúde Pública [...] (PEF 1).

Não estudei nem como se organiza o SUS, sua estrutura e funcionamento, a gestão. Tive que estudar sozinho e com a ajuda dos meus colegas de trabalho de outras áreas (PEF 2).

Estas lacunas e impropriedade na formação despertam surpresas e ansiedades para os profissionais:

Assim você entra em um novo campo de trabalho e fica surpreso com a quantidade de coisas novas que você não estudou, que você não conhece, que é importante para o trabalho. Novos conceitos, formas de trabalho, políticas públicas para a saúde, entre outras coisas. Aprendi no próprio campo de trabalho (PEF 2).

As afirmações do PEF 2 demonstram como o trabalho, entendido como princípio educativo, contribui para o refinamento da intervenção profissional, podendo ser potente e atuante na formação continuada em serviço. A esse princípio da formação para o trabalho, no próprio ambiente de ação, Bourdieu (1989) chamaria de construção do habitus profissional. $\mathrm{Na}$ fala do PEF 2 as interações sociais/profissionais que teve que estabelecer em busca da compreensão de sua intervenção no campo da SP demonstram serem fundamentais as relações, conteúdos e interações sociais realizadas com outros agentes/profissionais, com diferentes capitais e posições no campo (BOURDIEU, 1983).

O PEF 4 reforça essa importante questão alegando passar dificuldades na formação inicial "[...] pouco atenta às demandas do SUS e à intervenção da EF junto ao SUS [...] (PEF 4). O PEF 5 salienta não ter estudado disciplinas do campo da saúde mental e que as disciplinas "técnicas" ou metodológicas das práticas corporais ajudaram pouco para a atuação em saúde mental, embora tenham desempenhado importante papel na formação de um pensamento crítico-reflexivo. O PEF 6 traz à tona aspectos relacionados às disputas entre profissões quanto à exclusividade profissional na disputa por espaço (FREIDSON, 2001).Vejamos os fragmentos abaixo:

Eu tive um leque de disciplinas que me ajudaram um pouco, mas não tive nada de saúde mental, saí sem saber [...] tem matérias muito técnicas, mas eu acho que ajudou muito quanto ao pensamento crítico ajudou demais (PEF 5).

Se continuar do jeito que está nós vamos perder espaço [...]. Se não houver mudanças [...] a gente vai ter que mudar a nossa formação e tem que cuidar desses professores que estão atuando, tem que propiciar formação quem sai perdendo é o usuário. A formação não da conta da SP (PEF 6). 
Os recortes permitem indicar que essa formação restrita, apresentada acima, impede os estudos sobre a organização do SUS, a incorporação de novos conceitos, princípios e, consequentemente, formas de trabalho na SP, o entendimento de políticas públicas de saúde e questões complexas da gestão do SUS. Elucida também o entendimento da maioria dos PEF de que, não havendo preocupação com a mudança na formação inicial nos cursos de graduação, como consequência a profissão EF pode: "não dar conta do serviço", proporcionar perdas aos usuários ou, inclusive, correr sérios riscos de perder espaço para outras profissões neste campo. Este aspecto faz sentido se analisarmos sob o ponto de vista da Sociologia das Profissões. Isto porque, mesmo estando credenciado pela universidade com seus diplomas, tendo autonomia para atuar em SP, faltariam competências e habilidades não aprendidas na formação para ter eficiência na atuação e manter a exclusividade de seus serviços na SP.

Contudo, cabe destacar que suas afirmações demonstram pouca preocupação com o trabalho interprofissional e interdisciplinar, atualmente em voga na estruturação do trabalho no campo da SP. Inclusive com diversas experiências de incorporação nos serviços de saúde do SUS. Expressam, portanto, maior preocupação com a reserva de mercado e com o corporativismo profissional. Estas percepções podem ser reflexos das influências geradas pelos currículos tecnicistas e tradicionais do campo da EF.

Cabe destacar que esta formação tecnicista e tradicional na EF foi criticada pelos PEF 1, 4 e 7, sobretudo no que tange a: ênfase na abordagem da aprendizagem dos esportes com suas técnicas e táticas; construção de "planos de aula" (didática) de esportes formais e iniciação esportiva (PEF 1); conteúdos preconizados pelo sistema CONFEF/CREF que não são utilizados tais como do fitness, da atividade física, do exercício sistematizado e de medidas e avaliação (PEF 4); estrutura ideal que os cursos de formação tecnicistas "desenham na cabeça do profissional" com "quadra, área aberta, bolas e raquete, piscina, sala de dança com espelho para todo lado", não condiz com a realidade da SP (PEF 7).

Por outro lado, outros criticam a formação em licenciatura. Para os PEF, esta formação foca demasiadamente a atuação na escola e, portanto, reverbera nas dificuldades no trabalho especialmente quando precisam estruturar as ações no contexto da promoção da saúde. Em suas percepções, estas novas formas de trabalho fazem da atuação profissional um desafio no campo complexo da SP. Dizem que os conteúdos estudados na licenciatura não são fáceis, triviais e imediatamente transponíveis para o campo da SP. Nesta perspectiva, citam os exemplos das matérias de metodologia do ensino dos esportes, da natação, dos desportos e das competências físicas da área (PEF 2,7 e 9).

Fui formado para atuar especificamente na escola. Então muitas coisas não são aplicáveis assim como triviais. A natação, por exemplo, é difícil porque nos espaços da SP de Goiânia não tem essa estrutura. E outras matérias específicas do campo da EF não tem como colocar em prática (PEF 2).

Olha, a gente é formado para ser um professor de EF para atuar no desporto, nas competências físicas [...] a gente sabe a realidade da escola sem uma quadra, para trabalhar no sol, no terrão, diferente da Saúde Pública (PEF 7).

O olhar para o território aí você vem de uma formação na graduação mais voltada para 0 campo escolar e você se vê naquele lugar, não é o ideal porque, por enquanto, não tem essa posição por estarmos desbravando o campo e por causa da complexidade da SP (PEF 9). 
Acrescentamos uma questão de natureza sociológica para a qual se deve estar atento. Para os PEF haveria pouco preparo e formação voltada para atuar com os usuários nas unidades de saúde em detrimento da formação voltada para atuar com alunos de escola. Ou seja, a realidade das unidades de saúde, bem como a dos usuários, apresenta perfis e problemas sócio-econômico-culturais com os quais os profissionais não estão suficientemente aptos para lidar . Além deste aspecto, outro PEF reforça esta questão ao afirmar que o conteúdo e a tradição de formação mais escolar

[...] pouco se aplica para o trabalho com pacientes de hospital psiquiátrico devido aos efeitos adversos da medicação (PEF 4) [...] a debilidade fisiológica dos usuários não permite um planejamento bem organizado dos conteúdos a serem trabalhados, ou seja, é bem diferente do que se estuda na Faculdade (PEF 4).

Parece que a formação historicamente estruturada nos cursos de licenciatura com ênfase para a intervenção no campo escolar tem relação direta com a conformação do habitus profissional, no que Bourdieu (1983, p. 47) chamou de "sistema de disposições duráveis". Estas seriam incorporadas pelos sujeitos no meio social (neste caso na graduação) e estruturam as ações práticas para a realidade da escola. Assim, as dificuldades apresentadas pelos PEF demonstram aspectos estruturantes da formação do habitus profissional, pois a formação mais voltada para a escola gera uma "matriz de percepção e aspirações" para a ação (BOURDIEU, 1983, p. 65). Contudo, o autor alerta que esta matriz não corresponderia a um conjunto inflexível de regras de comportamento a serem indefinidamente seguidas (neste caso pelos PEF), portanto não seriam imutáveis. Isto porque o habitus, para este autor, seria formado por um conjunto de disposições gerais que precisariam ser "adaptadas" pelo sujeito a cada conjuntura específica de ação, o que chamou de "ato criativo".

Entendemos que existe nestas dificuldades uma estratégia possível de ser utilizada pelos PEF com vistas a estruturar suas ações na SP. Refletir que, como agentes sociais, seus habitus, construídos no campo acadêmico e fora dele, no passado sobrevivem no momento atual, atualiza-se nas práticas realizadas no presente e tende a subsidiar as ações e atos criativas futuros (BOURDIEU, 1983).

Diante destas questões, no entanto, destacamos que em outras unidades de saúde, que não trabalham com saúde mental, os conteúdos ligados à cultura corporal como 0 jogo, a dança, a ginástica, as lutas e os esportes, mais tematizados no campo escolar, têm forte inserção na atuação dos PEF, como vamos mostrar mais adiante.

Ainda sobre a formação inicial, o conflito formação ampliada x formação restrita, próprio do campo da EF, como não poderia ser diferente, apareceu nos discursos dos PEF 3, 4 e 5. Ponto que chamou à reflexão foi a defesa de uma formação generalista e ampliada na licenciatura, 0 que relativiza os aspectos da inapropriação da formação constatada anteriormente.

Alguns PEF indicaram que a formação inicial ampliada, crítica e com militância no movimento estudantil proporcionou buscar referenciais teóricos críticos, adaptar conteúdos e desenvolver a participação política e social, no cotidiano do trabalho em SP. Bourdieu (1989) chamaria de construção de um capital político. Também permitiu compreender melhor as possibilidades da EF na SP e a lógica de funcionamento, contradições e debilidades do SUS. Considerando os constructos autonomia, credencialismo e expertise profissional, defendidos por Freidson (1998) e inerentes ao campo da sociologia das profissões, indicamos que formação ampliada proporcionou aos PEF desenvolver prestígio e status no campo profissional. Mas a 
formação específica demonstra a importância da instituição formadora em credenciar e dar aportes com conhecimentos, conteúdos e metodologias que influenciem nas competências e habilidades para o exercício do PEF na SP. Vejamos as percepções dos PEF 3, 4 e 5:

\begin{abstract}
A formação na FEF (faculdade de EF da UFG) me deu uma formação ampliada e generalista. Os referenciais teóricos críticos me deram formação política e de conteúdos da EF que me ajudaram. Mas conhecimentos específicos para o trabalho no CAPs não estudei. Adaptei os conteúdos das metodologias do esporte, da dança e expressão corporal, ginástica para trabalhar com os usuários (PEF 3).

A formação em um curso de licenciatura de viés crítico e a militância no Movimento Estudantil contribuiu sobremaneira para compreender melhor as possibilidades da EF na SP, bem como compreender a lógica de funcionamento do SUS, suas contradições e debilidades (PEF 4).

[...] eu acho que ajudou muito quanto ao pensamento crítico ajudou demais, a UFG para mim eu sou suspeito porque gosto muito dela, [...] contribui muito para o meu trabalho (PEF 5).
\end{abstract}

Quanto às defesas da formação mais específica, o PEF 6 adverte sobre a necessidade de rever a formação quanto às disciplinas estudadas na graduação, em aspectos da expertise profissional em EF e visando ser mais eficiente no SUS. Defende a necessidade de ampliação do tempo de formação e o aumento do foco em disciplinas da área biológica e biodinâmica da atividade física, para a EF ser mais eficiente nos CAIS. Isto pode ser explicado, em parte, pelo fato dele trabalhar em uma unidade de saúde de média complexidade. Nesta, os aspectos biofisiológicos, bioquímicos e orgânicos são fundamentais no trato com os usuários portadores de doenças crônico-degenerativas. Vejamos sua ideia: "seis meses de anatomia, ossos e sistema é muito pouco [...]. Além da fisiologia humana, fisiologia do exercício e psicologia [...] para esse processo da saúde sinto falta de disciplinas como patologia" (PEF 6).

Não podemos desconsiderar as fragilidades da formação inicial anteriormente apresentada pelo PEF 6. Embora não suficientemente ensinadas nos conteúdos curriculares, estas disciplinas são fundamentais na formação do PEF, especialmente para aqueles que atuarão cotidianamente com usuários em nível de média e alta complexidade e podem proporcional status e autonomia neste campo de intervenção.

Outros entrevistados lembraram-se de disciplinas importantes que são estruturadas exclusivamente para a SP. Estas auxiliam os PEF no difícil papel de assumirem um campo de trabalho relativamente novo. Citaram disciplinas que, do ponto de vista mais prático, não teriam tanto valor para o tratamento de saúde dos usuários, como as danças circulares, jogos de salão, recreação e lazer. Lembram também das dinâmicas de grupo estudadas nas disciplinas ligadas ao campo da psicologia (aprendizagem e desenvolvimento humano). Vejamos nos trechos das entrevistas abaixo:

Danças circulares foi uma prática que eu fiz muito [...] e já tive vivências com danças circulares [...] com pacientes da área da saúde mental. Jogos de salão faço muito. Eu creio que uso muito tudo da área de recreação e lazer, [...] para pacientes agressivos estas atividades auxiliavam no tratamento (PEF 7).

[...] a recreação é muito importante, porque a gente tem aquelas aulas da época do Dalmo [professor]. Eu vejo a recreação sendo utilizadas no campo da psicologia como dinâmicas que eram as nossas brincadeiras das aulas de recreação (PEF 7). 
Em seu conjunto, os discursos evidenciam que a formação ampliada ou restrita, em parte, e não única e exclusivamente, sustenta ações desenvolvidas nas unidades de saúde. Sabemos o quanto SP é um tema complexo e controverso. Embora tenhamos identificado relativa percepção de fragilidades formação para atuar na SP, esta questão deve ser pensada com maior cuidado e cautela. Muitas disciplinas da formação em EF que, aparentemente e em um primeiro momento, não guardam relação com a SP, na verdade, estão descortinando uma visão muito mais ampla e complexa desse assunto. É o caso das disciplinas de lutas, ginástica, ioga, danças circulares, aprendizagens motoras e recreação, entre outras. Estas disciplinas referenciam e potencializam ações de promoção de saúde no trabalho no SUS justamente no que, historicamente, tem sido entendido como "abordagem ampliada da saúde" (FREITAS; CARVALHO; MENDES, 2013).

Por outro lado, os PEF defenderam que o próprio serviço contribui significativamente com a formação para a atuação, independentemente da recebida na universidade (acadêmica). Sobre este aspecto, a teoria da sociologia das profissões demonstra uma relação conflituosa entre os conteúdos acadêmicos e os aprendidos no ofício profissional. Pensando neste aspecto, Freidson (1998) indica haver uma dupla interdependência. Ou seja, os profissionais balizam suas ações nos conhecimentos aprendidos no campo acadêmico, mas também nos apropriados em ambientes de trabalho, serviços das unidades de saúde. Os fragmentos abaixo reforçam essa discussão:

Daí a importância dos acadêmicos das universidades estarem vindo para o serviço e do serviço abrir as portas para a universidade. Porque o profissional não precisa ter formação específica na área da saúde, mas sim entender o serviço e contribuir independente de sua formação (PEF 7).

[...] eu tenho este princípio de que a universidade deve estar próxima e não adianta ela trazer elementos teóricos para os alunos se eles não estão próximos do campo e da realidade de intervenção. Então a formação deveria ser junto do serviço e não anterior para depois intervir. Por isso a parceria é importante para colocar o aluno na realidade do serviço e em contato com os profissionais já formados (PEF 9).

Questionados sobre a adequação curricular à prática concreta do trabalho, defenderam a necessidade da formação privilegiar estágios em SP, visando conhecer os serviços e as demandas cotidianas enquanto estudantes. Para os PEF, estes permitiriam um olhar mais consistente, profissional e seguro na atuação na área de SP. Nesta questão, aproveitaram para criticar os cursos de formação excessivamente teóricos, com uma visão elitista e somente baseada na visão ideológica da "academia" (universidade), que credencia os profissionais. Ceccim e Bilibio (2004), discutindo sobre o processo de formação universitária, apontam ser um problema a ênfase nos procedimentos instrumentais na formação inicial. Indicam que gestores e os formadores em saúde não têm gerado suficiente contato dos acadêmicos com os serviços do SUS, tampouco a necessária familiaridade para que se componha como núcleo de práticas de cada profissão. Para os autores, trata-se de um paradoxo a ser superado, no qual a realidade de saúde e os recursos fundamentais de atuação no SUS permanecem desconhecidos dos estudantes, bem como têm se mantido a tradição e a conservação de conteúdos, disciplinas, conhecimentos e metodologias (CECCIM; BILIBIO, 2004, p. 9-10).

Entendemos, também, que parece haver uma contradição no que se refere à formação inicial no campo da EF. Há avanços significativos nas Políticas Nacionais de Saúde (BRASIL, 2008; BRASIL, 2007; BRASIL, 2005), incluindo os profissionais e a expertise da EF. Existem 
centenas de experiências do Pró-saúde e Pet-saúde que incluíram diversos cursos de EF de diferentes universidades brasileiras em projetos interprofissionais e interdisciplinares. Essas iniciativas buscaram aproximar a atuação do PEF às necessidades do SUS, contudo, parecem não gerar avanços estruturais e consistentes nos currículos de formação.

As iniciativas governamentais, em síntese, visam criar mudanças nas estruturações do processo de formação dos cursos da grande área da saúde. Propõem-se a diminuir a lógica do foco na doença e passar para a lógica da saúde estruturando as intervenções na perspectiva da saúde ampliada. As visões contraditórias que vimos na percepção dos PEF sobre a formação generalista/ampliada ou restrita/específica demonstram a necessidade do campo da EF rever seus currículos de formação, como assinala Rocha e Senturião (2007, p. 21-22). Diminuindo a exclusividade historicamente centrada em assuntos específicos/instrumentais como: a doença, órgãos e sistemas; sinais, sintomas, sequelas e medicalização; 0 ambiente clínico hospitalar. Fortalecendo a lógica da saúde ampliada, olhando para: sensações, percepções, movimentos e cultura; ações, funções e expressões; autonomia e espaço social/espaço de vida.

Em síntese, estas percepções dos PEF sobre o processo de formação em EF e suas relações com a atuação e, consequente, legitimação no SUS, exige "(re)pensar finalidades, pertinências e principais problemáticas [...]" (BAGRICHEVSKY, p. 33). Contudo, esta tarefa passa pelo desafio de entender que as mudanças são difíceis de acontecer em virtude dos embates travados por diferentes grupos, em diferentes momentos históricos, pelos intelectuais e profissionais com níveis de poder diferentes no campo. Parafraseando Bourdieu (1989) entendemos que reside nesta questão habitus e capitais estruturados e difíceis de serem repensados, se considerarmos os modismo e interesses hegemônicos do campo da EF brasileira.

\section{APONTAMENTOS FINAIS}

À guisa de conclusão, os PEF perceberam e apontaram as fragilidades na formação universitária quando relacionada à atuação profissional, especialmente por não problematizar o trabalho na perspectiva da SP. Em sua maioria, avaliam que os currículos são tradicionais e tecnicistas, especialmente voltados para temáticas mais centradas no campo da iniciação esportiva, atividade física, exercícios físicos, escola/didática e da academia de ginástica. Embora reconheçam a importância da EF na SP e alguns tenham feito críticas à formação específica e outros à formação ampliada, ponderamos que esta fragilidade pode ser muito mais explicada pela pouca história da EF no campo da SP e, como consequência, a pouca disseminação dos conhecimentos neste "relativamente novo" campo de intervenção profissional da EF.

Podemos inferir que, para os PEF trabalhadores da SP muitos conteúdos estudados na graduação que, em primeira vista, não fariam sentido na SP, têm uma aplicabilidade específica e de acordo com a realidade dos serviços de saúde. Todavia, outros, ao contrário, parecem óbvios na aplicação como as avaliações, medidas e protocolos de atuação (cartilhas) não funcionam como se preconiza na formação e nos documentos do conselho profissional. Em resumo, estes conteúdos não têm uma transposição fácil e clara para a atuação nas unidades de saúde.

Sobre estas problemáticas, a realidade tem demonstrado que estas dificuldades não são restritas à formação em EF, percebemos que os estudos sobre o SUS e SP ocupam um lugar de pouco prestígio na organização curricular que compõe os cursos de graduação da área da saúde em geral. 
Em uma conferência realizada na Faculdade de Educação Física e Dança (FEFD) da UFG, em Goiânia - 2014, no "I Seminário Internacional formação profissional no campo da EF", o professor Vicente Molina Neto contribui com a discussão quanto ao processo formativo dos PEF no Brasil. Argumentou existir, infelizmente, muitas influências na formação em nível de graduação. De tal modo que profissionais, instituições e outros organismos provocam a sua internacionalização. Molina Neto assinalou também, como consequências deste processo, a exacerbação do "produtivismo" acadêmico, os modismos curriculares ligados à empregabilidade, o "empreendedorismo" e a aceleração, quantificação e "latização da formação". Com isso a formação tem perdido elementos fundamentais para os PEF lidarem com a cultura corporal em contextos de ensino aprendizagem diversos. Por fim, em sua argumentação, acrescentou que a formação deveria ser revista visando privilegiar a reflexão sobre a experiência, os planos da autonomia dos acadêmicos, a problematização como centralidade metodológica, a qualidade dos conteúdos e a consideração das demandas sociais, comunitárias e dos contextos locais e as diversidades culturais.

Nossa investigação contribui para trazer à tona a percepção de PEF sobre as influências da formação inicial e da realizada nos lócus de atuação profissional em serviço de Saúde Pública, trazendo reflexões sobre as influências desses processos na atuação profissional. Gostaríamos de reconhecer os limites da investigação empreitada em um lócus limitado aos serviços de uma região da cidade de Goiânia. Por este motivo, mais esforços devem ser empreendidos para elucidar questões complexas que envolvem a relação entre a profissão EF e a intervenção destes profissionais em unidades de saúde do SUS brasileiro.

\section{REFERÊNCIAS}

BARDIN, Laurence. Análise de conteúdo. Lisboa: Editora Edições 70, 1977.

BAGRICHEVSKY, Marcos. A formação profissional em EF enseja perspectivas (críticas) para a atuação em saúde coletiva? In: FRAGA, Alex Branco; WACHS, Felipe (Org). Educação Física e Saúde Coletiva: políticas de formação e perspectivas de intervenção. 2 ed. Porto Alegre: UFRGS, 2007. p. 33-46.

BOURDIEU, Pierre. O poder simbólico. Trad. Fernando Tomaz. Rio de Janeiro: Bertrand Brasil, 1989.

BOURDIEU, Pierre. A procura de uma sociologia da prática. ORTIZ, Renato (org.). Pierre Bourdieu: sociologia. São Paulo: Ática, 1983.p. 7 - 37.

BRASIL. Ministério da Saúde. Portaria Interministerial, n. 1.802 de 26 de agosto de 2008. Institui 0 Programa de Educação pelo Trabalho para a Saúde-PET-Saúde. Diário Oficial da União, Brasília, DF, 27 ago. 2008. Seção 1. p. 27.

BRASIL. Ministério da Saúde. Programa Nacional de Reorientação da Formação Profissional em Saúde-Pró-Saúde: objetivos, implementação e desenvolvimento potencial 2007. Brasília, 2007.

BRASIL. Lei no 11.180, de 23 de setembro de 2005. Institui o Programa de Educação Tutorial PET e dá outras providências. Brasília. [on line]. 2005. Disponível em: <http://www. planalto.gov.br/ ccivil 03/ Ato2004 2006/2005/Lei/L11180.htm>. Disponível em: 20 fev. 2014. 
CECCIM, Ricardo Burg; BILIBIO, Luiz Fernando Silva. Articulação com o segmento estudantil da área da saúde: uma estratégia de inovação na formação de recursos humanos para o SUS. In: CECCIM, Ricardo Burg et al. (Org.). Ver-SUS Brasil: cadernos de textos. Brasília: Ministério da Saúde, 2004. p. 6-29.

CHIZZOTTI, Antonio. Pesquisa em ciências humanas e sociais. São Paulo: Cortez, 1995.

CIRQUEIRA, Márcio Vinicius B. Reflexões acerca da cultura corporal no espaço de atenção à Saúde Mental. In: RABELO, I. V.; TAVARES, Rosane, C.; FARIA, Y. R. A. de (Org.). Olhares-experiências de CAPS: Centro de Atenção Psicossocial. Goiânia: Kelps, 2009. p. 53-66.

COUTINHO, Silvano da Silva. Competências do professor de EF na Atenção Básica à Saúde. 2011. 207f. Tese (Doutorado) - Escola de Enfermagem de Ribeirão Preto, USP, São Paulo, 2011.

FONTANELLA, Bruno José Barcellos et al. Amostragem em pesquisas qualitativas: proposta de procedimentos para constatar saturação teórica. Cad. Saúde Pública, v. 27, n. 2, p. 389-394, fev. 2011.

FREIDSON, Eliot. A teoria das profissões: Estado da arte. Perfiles educativos, v, 23. n. 93, p. 28-43. 2001.

FREIDSON, Eliot. Renascimento do profissionalismo: teoria, profética e política. Tradução de Celso Mauro Paciornik. São Paulo: Editora da USP, 1998.

FREITAS, Fabiana Freitas; CARVALHO, Yara Maria de; MENDES, Valéria Monteiro. EF e Saúde: aproximações com a Clínica Ampliada. Revista Brasileira em Ciências do Esporte, v. 35, n. 3, p. 639-656, jul./set. 2013.

FURTADO, Roberto Pereira et al. O trabalho do professor de EF no CAPS: relatos de experiência. Movimento, v. 21, n.1, p. 41-52, jan./mar. 2015.

GOIÂNIA. Secretaria Municipal de Saúde. Diretoria de Gestão do Trabalho e Educação em Saúde. Divisão de Educação do Trabalho em Saúde. Relação de Profissionais Educadores Físicos. Goiânia, 2013.

MARTINEZ, Jéssica Felix Nicácio. Educação Física e Saúde Pública: a inserção do profissional de EF em um núcleo de apoio à saúde da família (Goiânia/GO). 2014. 289 f. Tese (doutorado). Programa de Ciências da Saúde. Universidade Federal de Goiás. 2014.

ROCHA, Vera Maria da; CENTURIÃO, Carla H. Profissionais da saúde: formação, competência e responsabilidade social. Educação Física e Saúde Coletiva. In: FRAGA, Alex Branco;WACHS Felipe (Org.). Políticas de Formação e Perspectivas de Intervenção. 2 ed. Porto Alegre: UFRGS, 2007. p.17-32 .

TEIXEIRA, Elizabeth. As três metodologias: acadêmica da ciência e da pesquisa. 3. ed. Belém: Grapel, 2001.

TRIVIÑOS, Augusto Nibaldo Silva. Introdução à Pesquisa em Ciências Sociais: a Pesquisa Qualitativa em Educação. São Paulo: Atlas, 1987.

Apoio:

Coordenação de Aperfeiçoamento de Pessoal de Nível Superior (Capes), fundação do Ministério da Educação (MEC). 